Ключевые слова: причинно-следственная связь, иерархия уровней общности причинно-следственных связей, строение субъектной причинности, строение объектной причинности.

\title{
THE STRUCTURE OF THE CAUSE AND EFFECT LINK IN THE CAUSALITY THEORY OF CRIMINALISTICS
}

Velikanov $S$. $V$.

The article deals with the issues of the cause and effect link structure in the causality theory of criminalistics. It identifies similarity levels for causality as well as their hierarchy. Within the context of subject's instrumental causality the link structure is represented by related events "the subject's decision», "the subject's action», "the use of the means», "the formation of the trace». Within the context of the subject causality without instruments the article discusses the links between the events "the subject's decision» - "the subject's actions» - "the formation of the trace». The context of object causality links the events "the object's actions» and "the formation of the trace». The link «the subject's decision» - «the subject's actions» in subject causality is described as a mental phenomenon and with this regard the article provides arguments in favor of compatibility of the subject's free will and determinism. The other links that are discussed in the article are of deterministic nature, as they take place while interacting with material objects and are governed by natural laws. The article determines the areas and branches of criminalistics where these contexts of cause and effect links are the most common.

Keywords: cause and effect link, hierarchy of similarity levels for cause and effect links, structure of subject causality, structure of object causality.

УДК 343.98 .06

Я. E. Мышков, начальник отдела Следственного управления прокуратуры Харьковской области, кандидат юридических наук

\section{ПРОБЛЕМЫ ОПТИМИЗАЦИИ СЛЕДСТВЕННЫХ ДЕЙСТВИЙ В МЕТОДИКЕ РАССЛЕДОВАНИЯ ПРЕСТУПЛЕНИЙ}

Рассмотрены основные проблемы, относящиеся к понятию и способам формирования систем следственных действий, применение которых способствует эффективности расследования преступлений. В этой связи названы источники формирования систем, функции последних в решении мыслительных задач, относящихся к расследованию. Даны рекомендации о возможности алгоритмизации систем следственных действий.

Ключевые слова: системы следственных действий, расследование преступлений, возможности алгоритмизации.

(с) Мышков Я. Е., 2015 
В методике расследования преступлений недостаточно разработана проблема систем следственных действий, которые являются способом получения доказательственной информации. Названная проблема фрагментарно исследуется в работах Р. С. Белкина, В. В. Тищенко, Г. А. Матусовского, В. Ю. Шепитько, В. А. Журавля и др. ${ }^{1}$

Целью статьи является новое рассмотрение проблемы систематизации следственных действий и использования последних в целях оптимизации расследования преступлений.

Методика расследования отдельных видов преступлений, как и методика расследования вообще, является своего рода основной частью криминалистической теории, разрабатывающей проблемы техники и тактики расследования. Синтез знаний, адаптируемых в методике расследования, означает их планирование и организацию с целью совершенствования расследования преступлений, сокращения его сроков, использования проблем планирования и организации последнего.

Методика расследования в процессе своего формирования основывалась на анализе деятельности следственной практики, предполагающем как обобщение передового опыта расследования, так и допускаемых в ходе следствия недостатков (ошибок). В этом плане уже первые учебники криминалистики имели соответствующие разделы, посвященные проблемам методики расследования².

Следует отметить, что рождение методики расследования как концепции, составляющей теорию криминалистики, мы обнаруживаем в первых инструкциях для народных следователей, издания которых относятся к 19191921 гг. Так, Инструкцией о народных следователях НКЮ УССР 1919 г. были введены отдельные положения, относящиеся к возбуждению уголовного дела, тактике производства отдельных следственных действий, в том числе осмотру места происшествия, допросу и другим при расследовании преступлений ${ }^{3}$. Первые в этом отношении шаги, обозначенные в названных инструкциях, явились предпосылкой для формирования в последующем как Уголовно-процессуального кодекса 1922 г., так и первых работ по кримина-

1 См.: Белкин Р. С. Курс криминалистики : в 3 т. / Р. С. Белкин. - М. : Юристъ, 1997; Тищенко В. В. Теоретичні і практичні основи методики розслідування злочинів : монографія / В. В. Тищенко. - Одеса : Фенікс, 2007; Криминалистика. Криминалистическая тактика и методика расследования преступлений : учебник / [В. Н. Глибко, Г. А. Матусовский и др.] ; под ред. В. Ю. Шепитько. - Х. : Одиссей, 2001. - 528 с. Из содерж.: Гл. 9-13, 17-19, 26, 28 / Г. А. Матусовский. - С. 176-235, 282-352, 453-472, 507-518; Шепітько В. Ю. Криміналістика : підручник / В. Ю. Шепітько. К. : Ін Юре, 2010; Журавель В. А. Криміналістичні методики: сучасні наукові концепції / В. А. Журавель. - Х. : Апостіль, 2012. - С. 204-222.

2 См.: Якимов И. Н. Криминалистика. Руководство по уголовной технике и тактике / И. Н. Якимов. - М. : Изд-во НКВД РСФСР, 1925; Криминалистика / под ред. А. Я. Вышинского. - М. : Юрид. изд-во НКЮ СССР, 1938; Криминалистика / под ред. А. И. Винберга, С. П. Митричева. - М. : Госюриздат, 1950.

См.: Коновалова B. E. Некоторые вопросы истории советской криминалистики (1917-1920 гг.) // Учен. зап. Харьк. юрид. ин-та. — Х., 1957. — Т. 11, Вып. 2. C. $66-75$. 
листике, в частности на уровне учебника'. Последующее формирование методики расследования как раздела криминалистики мы обнаруживаем в учебниках, главными из которых являются «Криминалистика» под редакцией А. Я. Вышинского (1938) и А. И. Винберга (1950).

Формирование методики расследования преступлений как раздела науки связано с острыми научными дискуссиями по поводу становления криминалистики как науки и выяснения ее предмета и научных функций ${ }^{2}$.

Названные дискуссии вызвали к жизни многочисленные попытки исследования предмета криминалистики, таких ее разделов, как криминалистическая техника, криминалистическая тактика, и подходов к проблемам методики расследования преступлений. Фрагментарный генезис этапов развития методики расследования преступлений завершается к настоящему времени ее новыми определениями, выяснением ее структуры, сущности и задач. В этом отношении представляет интерес определение методики расследования как раздела криминалистики, данное Г. А. Матусовским, который рассматривал методику как двухуровневую область знания. С одной стороны, как общую методику расследования преступлений, с другой - как методику расследования отдельных видов преступлений, конкретизируя основные их положения применительно к каждой из названных отраслей. При этом в работе не выделялись данные, относящиеся к месту в названных системах отдельных, следственных действий, составляющих, по нашему мнению, основу получения доказательственной информации, определяющей успех расследования³.

Иную позицию занимает В. Ю. Шепитько, рассматривая криминалистическую методику как «систему теоретических положений и разрабатываемых на ее основе рекомендаций организации и осуществления расследования и предупреждения отдельных видов преступлений», не называя общей методики расследования преступлений и отдельных ее видов ${ }^{4}$. Вместе с тем в изложении системы методики автор впервые называет в числе отдельных положений методики расследования «типовые комплексы следственных действий и оперативно-розыскных мер, предусматривая последовательность их выполнения» ${ }^{5}$. Эта новация способствует образованию более стройной научной системы методики расследования преступлений, ее законченности и практической важности.

Наряду с приведенным, в криминалистической литературе и сейчас высказываются предложения о введении в структуру методики расследования преступлений отдельного положения, связанного с формированием

1 См.: Якимов И. Н. Указ. работа.

2 См.: Шавер Б. М. Предмет и метод советской криминалистики / Б. М. Шавер. // Соц. законность. - 1938. - № 6. - С. 56-82.

3 См.: Криміналістика : підручник / [В. М. Глібко, Г. А. Матусовський та ін.] ; за ред. В. Ю. Шепітька. — К. : Ін Юре, 2001. — С. 176-177.

4 Шепітько В. Ю. Криміналістика : підручник. - С. 337.

5 Там же. - C. 322. 
систем следственных действий и их взаимосвязи в расследовании. Примечательно, что в новых исследованиях достаточно подробно рассматриваются вопросы относительно традиционных систем следственных действий в криминалистической методике и их возможных модификациях в соответствии с существующими следственными ситуациями. Так, В. А. Журавель утверждает, что традиционным элементом структуры отдельной криминалистической методики является система следственных действий, объясняя это тем, что последняя выполняет познавательную функцию в расследовании преступлений ${ }^{1}$.

Отмеченное ранее позволяет прийти к выводу о многообразии определений структуры методики расследования преступлений, а определение методики рассматривать как систему научных концеециий, определяющих сущность и функции расследования преступлений. Представляется, что названное определение в наиболее лаконичном виде охватывает как общую систему методики расследования, так и ее систему в методике расследования oтдельных видов преступлений.

В методике расследования преступлений особое внимание обращают на себя следственные действия и их возможные системы, выполняющие главную познавательную роль в процессе собирания и оценки доказательственной информации. Известно, что объем информации (достаточный, недостаточный, полное отсутствие) определяет не только начало расследования, но и дальнейшее его развитие, в частности проверку имеющихся версий, выдвижение новых, окончание расследования. Поэтому именно комплексу следственных действий как инструменту извлечения доказательств и должно принадлежать одно из главных мест в научных положениях методики расследования.

Процесс формирования комплекса следственных действий в методике расследования отдельных видов преступлений, по нашему мнению, зависит от нескольких определяющих положений: а) от предмета расследования (вид преступной деятельности, вид преступления); б) от ситуационной зависимости (комплекс доказательственной информации на данный период расследования), в том числе оценки комплекса как уровня доказательственной ценности имеющихся доказательств по убеждению следователя; в) от тактической оптимальности избираемого комплекса следственных действий, т. е. оптимальной последовательности следственных действий с позиции их внезапности предполагаемой важности добытой информации - результативности выполняемого комплекса.

Рассмотрим приведенные положения более детально. Так, каждое преступление индивидуально по своему виду, способам совершения и результатам (последствиям). Названная индивидуальность предопределяет наличие традиционных следственных действий, направленных на обнаружение доказательственной информации. Традиционность определяется, в свою очеC. 205.

${ }^{1}$ См.: Журавель В. А. Криміналістичні методики: сучасні наукові концепції. - 
редь, видом преступления и комплексом прогнозируемой доказательственной информации, которая может сопровождать события. Так, доказательственная информация при расследовании взяточничества может определяться характером преступления и теми следами, которые сопровождают это событие преступления: показаниями свидетелей и вещественными доказательствами (предметы взятки, наличие следов на этих предметах - пальцев рук, специальных химических средств).

При расследовании убийств традиционными следами могут быть показания свидетелей, наличие орудия убийства, наличие трупа, наличие крови и других вещественных доказательств. В этой связи, исходя из вида преступления, формируются как отдельные следственные действия (допросы свидетелей, назначение экспертиз), так и возможные их системы, включающие их последовательность. Поскольку практика преступных посягательств обладает разнообразием, то и комплекс следственных действий или их система соответствуют этим разновидностям. Так, при расследовании убийств такие виды преступлений, как убийства с расчленением трупа, убийства с инсценировкой самоубийства, убийства по заказу, убийства, совершенные организованной преступной группой, имеют своеобразный комплекс следственных действий, который по рекомендациям криминалистической методики может быть наиболее целесообразным.

Как отмечалось, системы следственных действий, как и отдельные следственные действия, которые выполняет следователь, зависят от следственной ситуации. В криминалистической литературе проблеме следственных ситуаций посвящено значительное количество теоретических исследований, в которых понятие «следственная ситуация» рассматривается по-разному. Сущность формулирования таких определений зависит от понимания авторами самого понятия следственной ситуации. В основном мнения авторов разделяются в зависимости от того, рассматривается ли следственная ситуация достаточно широко либо сосредоточена только на объеме доказательственной информации. При первом понимании понятие «следственная ситуация» включает обстановку события и другие параметры, характеризующие ее. Другое понимание сосредотачивает понятие «следственной ситуации», как комплекс доказательственной информации на определенном этапе расследования преступления. Как представляется, второе определение ситуации обладает большей информационной сущностью, чем первое, сосредотачивая внимание на объеме и значении того доказательственного материала, который является основой для мыслительной деятельности следователя. Это очевидно, так как анализ и оценка полученных в результате расследования данных позволяют ориентировать деятельность следователя по дальнейшему расследованию. Определения следственных ситуаций как конфликтных, бесконфликтных, тупиковых и других, скорее всего, относятся к ситуациям отдельных следственных действий, а не к расследованию в целом.

Развитие тематики следственных ситуаций нашло свое отражение в новых подходах к методике расследования отдельных видов преступлений. 
Такой новеллой в структуре методики является, так называемый «ситуационный подход к расследованию преступлений» ${ }^{1}$.

Это толкование, как новый оригинальный подход к расследованию в той или иной отдельной методике, заслуживает внимания, однако его сложность заключается в понимании сущности исходных следственных ситуаций, позволяющих осуществлять расследование наиболее эффективно.

Достаточно убедительные соображения о возможности и значимости ситуационного подхода в расследовании отмечают также Т. С. Волчецкая, Л. Я. Драпкин, В. А. Журавель и др. ${ }^{2}$

Ситуационный подход в расследовании, как представляется, непосредственно зависит от характера имеющейся доказательственной информации, а следовательно, от отдельных следственных действий и их систем, с помощью которых получена необходимая информация, составляющая ситуацию.

Поскольку системы следственных действий, предполагающие определенную очередность их проведения, должны выполнять свои функции, большое значение имеет их планирование. Последнее означает прогнозирование их возможной эффективности на том или ином этапе расследования. Решение мыслительных задач, связанных с прогнозированием их результативности, включает в себя элементы рефлексивного мышления, обозначающего получение возможных результатов. Именно это позволяет правильно планировать применение как отдельных следственных действий, так и их систем.

Следует отметить, что к системам следственных действий непосредственно примыкают и тактические операции, а также тактические решения, анализ которых предполагает наибольшую эффективность использования в расследовании.

В планировании расследования очередность проведения отдельных следственных действий или их систем (последовательное проведение двух или трех следственных действий) имеет значение для возможного получения доказательственной информации при использовании периода (этапа) расследования, которые по мнению следователя могут быть наиболее эффективными. При этом имеются в виду такие позиции, как внезапность применения этих систем, возможная сила их психологического воздействия, неожиданность для подозреваемого, который не подготовил соответствующих возражений, и др.

1 См.: Волчецкая T. С. Ситуационное моделирование в расследовании преступлений : автореф. дис. на соискание уч. степени канд. юрид. наук : спец. 12.00.09 «Уголовный процесс и криминалистика. Судебная экспертиза» / Т. С. Волчецкая. М., 1991. - С. 23; Шепітько В. Ю. Криміналістика : підручник.

2 См.: Драпкин Л. Я. Основы криминалистической теории следственных ситуаций : автореф. дис. на соискание уч. степени д-ра юрид. наук : спец. 12.00.09 «Уголовный процесс и криминалистика. Судебная экспертиза» / Л. Я. Драпкин. - М., 1987. - 46 с.; Волчецкая T. С. Криминалистическая ситуалогия : монография / Т. С. Волчецкая ; под ред. Н. П. Яблокова. - Калининград : , 1997. - 248 с.; Журавель В. А. Криміналістичні методики: сучасні наукові концепції. - С. 186-203. 
Тактическая зависимость систем следственных действий от этапа расследования, ситуации позволяет моделировать их при всем разнообразии. Моделирование как соответствующая программа применения систем следственных действий может способствовать составлению их возможных алгоритмов, которые могут дать в распоряжение следователя типичные варианты тактики применения систем следственных действий ${ }^{1}$.

Применение систем следственных действий, которые созданы самим следователем на основании опыта следственной деятельности либо получены им из научных рекомендаций, выполняют еще одну важную функцию в расследовании - экономию процессуальных средств. Эта позиция обусловлена сложным процессом решения мыслительных задач, осуществляемых следователем при расследовании преступлений. Таким образом, основаниями для формирования систем следственных действий являются научное обобщение передовой следственной практики и ее анализ, а также собственный опыт следователя, создающие экспериментальную базу для рекомендаций по совершенствованию следственной деятельности.

\section{ПРОБЛЕМИ ОПТИМІЗАЦІЇ СЛІДЧИХ ДІЙ У МЕТОДИЦІ РОЗСЛІДУВАННЯ ЗЛОЧИНІВ}

Мишков Я. $Є$.

Розглянуто основні проблеми щзодо поняття і способів формування систем слідчих дій, застосування яких сприяе ефективності розслідування злочинів. У зв'язку з иим названо джерела формування систем, функиії останніх при виріменні розумових завдань, що стосуються розслідування. Дано рекомендаиії з можливості алгоритмізаиії систем слідчих дій.

Ключові слова: системи слідчих дій, розслідування злочинів, можливості алгоритмізаиії.

\section{THE PROBLEMS OF OPTIMIZING INVESTIGATION ACTIONS IN THE METHODOLOGY OF CRIME INVESTIGATION}

\section{Myshkov Y. E.}

The article deals with the main problems related to the notion and ways of forming the system of investigation actions, the use of the latter contributes to the efficiency of crime investigation. It describes the sources of the formation systems of investigation actions, their functions in the resolution of intellectual tasks within the investigation. The article points to the role of planning the

1 См.: Коновалова В. Алгоритмізація в теорії криміналістики / В. Коновалова // Вісн. Акад. прав. наук України. - Х. : Право, 2007. - Вип. 1(48). - С. 169-174; Шепітько В. Ю. Проблеми алгоритмізації слідчої діяльності / В. Ю. Шепітько, Г. К. Авдєєва // Актуальні проблеми держави і права : зб. наук. праць. - Одеса : Юрид. літ., 2008. - Вип. 44. - С. 46-50; Журавель В. Проблеми алгоритмізації та програмування розслідування злочинів / В. Журавель // Вісн. Акад. прав. наук України. — Х. : Право, 2008. - Вип. 2(53). - С. 191-200. 
systems of investigation actions to investigate into specific crimes, namely, their order, possible effectiveness, expected results and applicability in the investigation. The article underscores the role of reflective thinking in estimating the expected effectiveness of their use. It is important to note that criminalistic publications have two perspectives on the formation of the concept of Methods to investigate crimes: 1) general methods for investigating crimes; 2) methods for investigating individual types of crimes. The latter concept has received much of the attention of researchers, though it lacks section of the system of investigation actions that is included only in the most recent monographs and textbooks, this once again proves its relevance as a subject for further research. The article provides recommendations on the developing of an algorithm for the system of investigation actions.

Keywords: system of investigation actions, crime investigation, algorithm facility.

УДК 343.985:343.62

B. В. Пясковський, заступник начальника кафедри криміналістики та судової медицини Національної академії внутрішніх справ, кандидат юридичних наук, доцент

\section{ТАКТИЧНІ ОСОБЛИВОСТІ ДОПИТУ НЕПОВНОЛІТНІХ ПОТЕРПІЛИХ ВІД НАСИЛЬНИЦЬКИХ ЗЛОЧИНІВ}

Розглянуто загальні тактичні умови проведення допиту неповнолітніх потерпілих під час розслідування насильницьких злочинів. Обтрунтовано, щцо для його успішного виконання слідчому необхідно звернути увагу на обрання місия й часу проведення запланованої дії та необхідну формуи взаємин із неповнолітнім, ступінь взаємодії з батьками (законними представниками) неповнолітнього учасника, кількість присутніх.

Ключові слова: криміналістична тактика, насильницькі злочини, допит, неповнолітній потерпілий, дитина, слідча (розшукова) дія.

Як показує слідча практика, усе частіше й частіше працівники правоохоронних органів змушені допитувати дітей, які стали жертвами різних злочинів або є єдиними свідками злочину. Однак проведення слідчих (розшукових) дій (особливо допиту) за участю таких потерпілих часто викликає в слідчих і співробітників оперативних підрозділів труднощі, пов'язані з незнанням ними особливостей спілкування з подібним контингентом учасників кримінального процесу.

У зв'язку з цим досвід діяльності працівників правоохоронних органів багатьох європейських держав свідчить про те, що вміле спілкування з неповнолітніми потерпілими від злочинів значною мірою може допомогти в досягненні завдань кримінального судочинства в конкретному криміналь-

(C) Пясковський В. В., 2015 